\title{
Formation of a health-preserving environment in preschool educational institutions.
}

\author{
Victoria Martynova ${ }^{1 *}$, Farida Gazizova ${ }^{2}$, Tatyana Galich $^{2}$ \\ ${ }^{1}$ Kuban State University of Physical Culture, Sports and Tourism, 350015, Krasnodar, Russia \\ ${ }^{2}$ Yelabuga Institute of Kazan Federal University, 423600, Yelabuga, Russia
}

\begin{abstract}
The paper considers the use of health-saving environment in preschool educational institutions. The health-preserving environment model allows a child to develop favorably in a preschool educational institution. In the process of testing this model, we used the following research methods: analysis of scientific and methodological literature, morphofunctional indicators, analysis of physical fitness, methods of mathematical statistics. Initial analysis of morphofunctional indicators showed that all indicators meet the standards for this age of children, but the level of these indicators is not high enough. The analysis of physical indicators of preschool children corresponds to the average value for this age, but a large percentage cannot meet these requirements for the level of physical fitness. We obtained positive results in the course of the experiment for all the studied indicators, after the introduction of our model.
\end{abstract}

\section{Introduction}

The problem of younger generation's health forming is the main task of the state policy in modern Russian society. It affects the health system as well as the preservation of health in the process of learning.

In 2011 Federal law of the Russian Federation No. 323-FZ "The basics of public health protection in the Russian Federation" was introduced. Since then, the state carries out a large number of preventive measures in the field of child health, but these measures do not reduce the incidence of children and adolescents.

According to the Federal state statistics service, the increase in the incidence of children under 14 years in Russia increased significantly to 38225.7 thousand children. The incidence is also observed among the adult population [1].

Among the child population according to the Federal state statistics service, the morbidity by main disease classes in 2000 - 2017 was the following: in 2010, more than 38,000 cases, in 2017 reached 44919,0 cases; the diseases of the respiratory system in 2010 - 21347,2 cases, in 2017 - identified 30006,9 cases; diseases of the circulatory system 2010 - 172,5 $2017-189$ cases [2].

As Aizyatullova G. R., Sudar V. V. note that due to the deterioration of the younger generation health in the XXI century, the development and implementation of new methods and technologies, alternative approaches to improving the process of physical education of children becomes a priority in preschool education $[3,4]$.

The implementation of health technologies in the educational environment of preschool educational institution is a very important issue. It is considered as a complex system of educational, corrective and preventive actions implemented in the process of interaction between pupil and teacher, child and parents, preschooler and a medical professional. This system is considered as a continuous and consistent interaction of parents, doctors, teachers, psychologists and others who are called to carry out health-saving activities in preschool institutions aimed at preserving and strengthening children's health $[5,6]$.

There are quite a lot of studies devoted to the search for innovative means, methods and organizational forms of preschool children physical education.

Authors Bezrukikh M. M., Loginova E. S. in their article claim that the senior preschool age is considered as an important stage of child's functional development and a significant stage of psychological and social readiness for school education. Child development before school is a predictor of overall learning success, social adaptability, and emotional stability [7].

The authors note that children of preschool age have an optimal level of physical development in $61.7 \%$.

Researchers Sonkin V. D., Zaitseva V. V. in their work show that the level of physical development decreases with age, especially during school education [8].

This tendency to reduce the level of child's functional indicators is reflected in the works of scientists Kuznetsova O. V., Sonkin V. D., Kovalenko T. G., Shklyarenko A. P., Ulyanov D. A., Degtyarenko Yu. G. and D. R. [9,10].

Bezrukikh M. M., Ivanova R. recommend considering the child's physical development from a physiological, cognitive, socio-personal points of view. The author claims that at the age of 6-7 years, children continue to develop and improve actively, ensuring readiness for school. But a number of works confirmed the relationship between speech, social and communicative and physical development [11,12].

* Corresponding author: victoria_martynova@yandex.ru 
The works of Kuznetsova Z. M., Zolotova V. N., Sudar V. V., reflect the problems of physical culture and health technologies use in preschool age and ways to solve them [13,14,15-18].

The introduction of educational standards in preschool education promotes the development of personal-social and physical development of the child. The demands of pre-school education to the level of teachers professionalism also increase. This fact activates the health-preserving technologies searching.

\section{Materials and methods}

The purpose of our research is to test the health-saving model of physical education in the system of preschool educational institutions.

Methods and organization of research: analysis of scientific and methodological literature; systematization and analysis of scientific and methodological literature on this problem, analysis of physiological indicators; mathematical and statistical processing.

The physical development of children was evaluated using anthropometric indicators. Anthropometry was performed in accordance with the guidelines for the all-Russian system of monitoring the physical development and physical fitness of children, adolescents and youth. Anthropometric measurements were performed to assess the level of children's physical development according to the generally accepted method using standard tools. They were evaluated: ZHEL (mll), Romberg test, Skibinsky index, height, body weight. To assess the impact of this model, we also considered the level of physical fitness, according to the main indicators recommended for this age.

The research was carried out in several stages, conducted among preschool educational institutions in Nizhnekamsk. The study involved 400 children (4-6 years old). The study was conducted from September 2016 to May 2018. Groups where this experiment was not performed (control groups) are highlighted.

The study was based on an experiment that was conducted over a year. The health status of the referents was determined by medical professionals, since the experiment was conducted under the supervision of doctors.

This model is an integral structure: the goal, objectives, principles, pedagogical conditions, orientation of the educational process subjects, forms and methods of the educational institution, management system, evaluation criteria for this model, the planned result. Much attention is paid to scientific and methodological support of the entire process of upbringing and improving children's health.

We set a number of conditions for this model working effectively in the direction of creating a health-saving environment in a preschool educational institution:

- it is necessary to involve all interested people in the problem of education and create a favorable environment for the younger generation;

- scientific and methodological support of preschool educational institutions by specialists in this field;

- socio-pedagogical condition, the variability of the educational process content, the choice of effective technologies for creating a comfortable environment for pupils, taking into account their social status;

- medical and pedagogical support of the educational process. It implies ensuring the physiological and psychological adequacy of the child in a changing world,

- formation of cognitive interests and cognitive actions of the child in various activities based on the age adequacy of preschool education;

- formation in the process of training students ' trajectory to preserve their health, as well as to form the ability to self-control over the state of health;

- creation of sanitary and hygienic conditions in the educational institution that favorably affect the psychological comfort of students;

- competent planning, organization and management contribute to the development of the child, without loading various unbalanced activities.

This model of forming a health-preserving environment is implemented on the basis of the above conditions.

The practical significance of the research results lies in the possibility of applying the results to build a healthpreserving environment in a preschool educational institution.

\section{Results and discussion}

During the experiment, we studied the level of physical fitness and the level of functional indicators.

As a result of this model implementation we found the following changes in indicators for girls: in the first year of the experiment, the Skibinsky index increased to $14 \%$, in the second year this indicator increased to $44.3 \%$, in the control group 9-18. $2 \%$. This indicates the functional capabilities of the respiratory and circulatory organs.

In the experimental group, the increase in this indicator was $38 \%$ for the entire period of the experiment, in the control group, the indicator is up to $11 \%$ for the entire period of the experiment.

In the process of reviewing the indicator of the respiratory system level, we found that this indicator in the experimental group increased by $36.7 \%$, in the control group this indicator was $10.3 \%$.

The indicator of the boys' respiratory system in the experimental group increased by $32.53 \%$ while in the control group this indicator increased by $23.8 \%$.

Analysis of the Romberg test in girls showed an increase of $45.7 \%$ from the initial level, in the experimental group, while in the control group the increase for this period was $15.4 \%$.

In the Romberg test, the indicator for boys in the control group was $16.9 \%$, but in the experimental group the indicator increased by $44.8 \%$. 
When considering the Quetelet mass index we found no significant differences between the experimental and control groups.

We did not find significant differences in the Quetelet index, but we found significant changes in the Skibinsky, lung capacity and Romberg tests. The data is shown in figure 1.

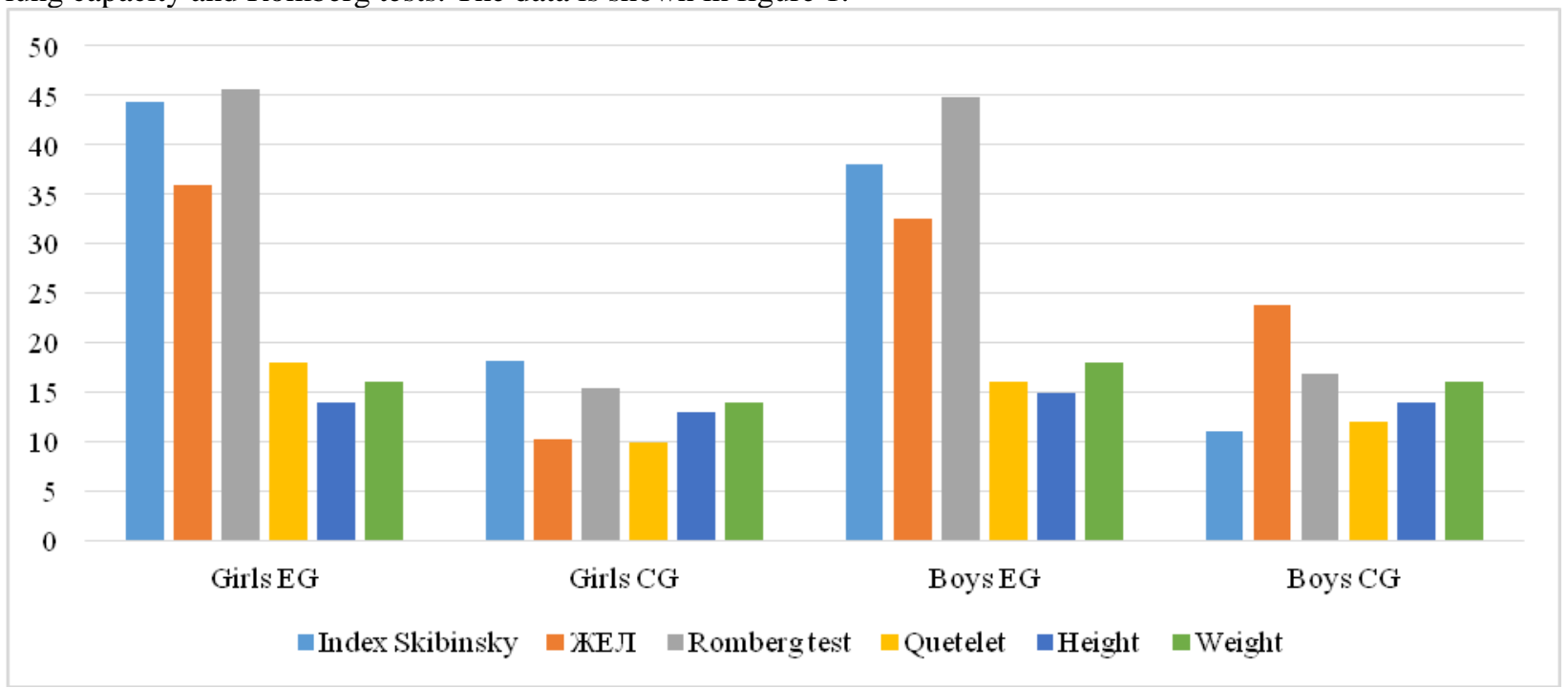

Fig. 1. Dynamics of growth of morphofunctional indicators during the experiment

The analysis of physical fitness was carried out according to the following indicators: $30 \mathrm{~m}$ running, $10 \mathrm{~m}$ running between objects, long jump from a place, throwing the bag into the distance, flexibility.

Analysis of the indicator running at $30 \mathrm{~m}$., in boys of this age in the experimental group showed an increase of $26 \%$, in girls the increase was $29 \%$. In the control group, this indicator improved by $10 \%$ in girls and $12 \%$ in boys.

Analysis of the movement coordination index in the given age, running for $10 \mathrm{~m}$ between subjects showed that in the experimental group, the increase in girls was $26 \%$, in boys $-32 \%$. it should be noted that in the experimental group, the increase is lower. For girls in the first year, the increase was 5\%, for the entire period $11 \%$, for boys $8 \%$ and $18 \%$ for the entire period.

The indicator that characterizes the strength component for this age-the long jump, showed that the experimental group is ahead of their peers in this indicator. The increase in boys was $28 \%$, and in girls $32 \%$, in the control group the increase was $18 \%$ and $16 \%$ for this indicator.

The following values were obtained in the distance throwing indicator, so the increase in the control group in boys during the experiment was $12 \%$, in the experimental group the indicator was $32 \%$. In girls of this age, this indicator is significantly lower, so in the experimental group the indicator was $22 \%$, in the control group $18 \%$.

The study of the flexibility indicator in this group showed that the increase in the control and experimental groups in comparison with other indicators is more significant. So in the experimental group, the increase over the period of the experiment in boys is $44 \%$, in girls $49 \%$, in the control group the indicator is $38 \%$ and $42 \%$. The data shows the sensitive period of this indicator. The data is shown in figure 2 .

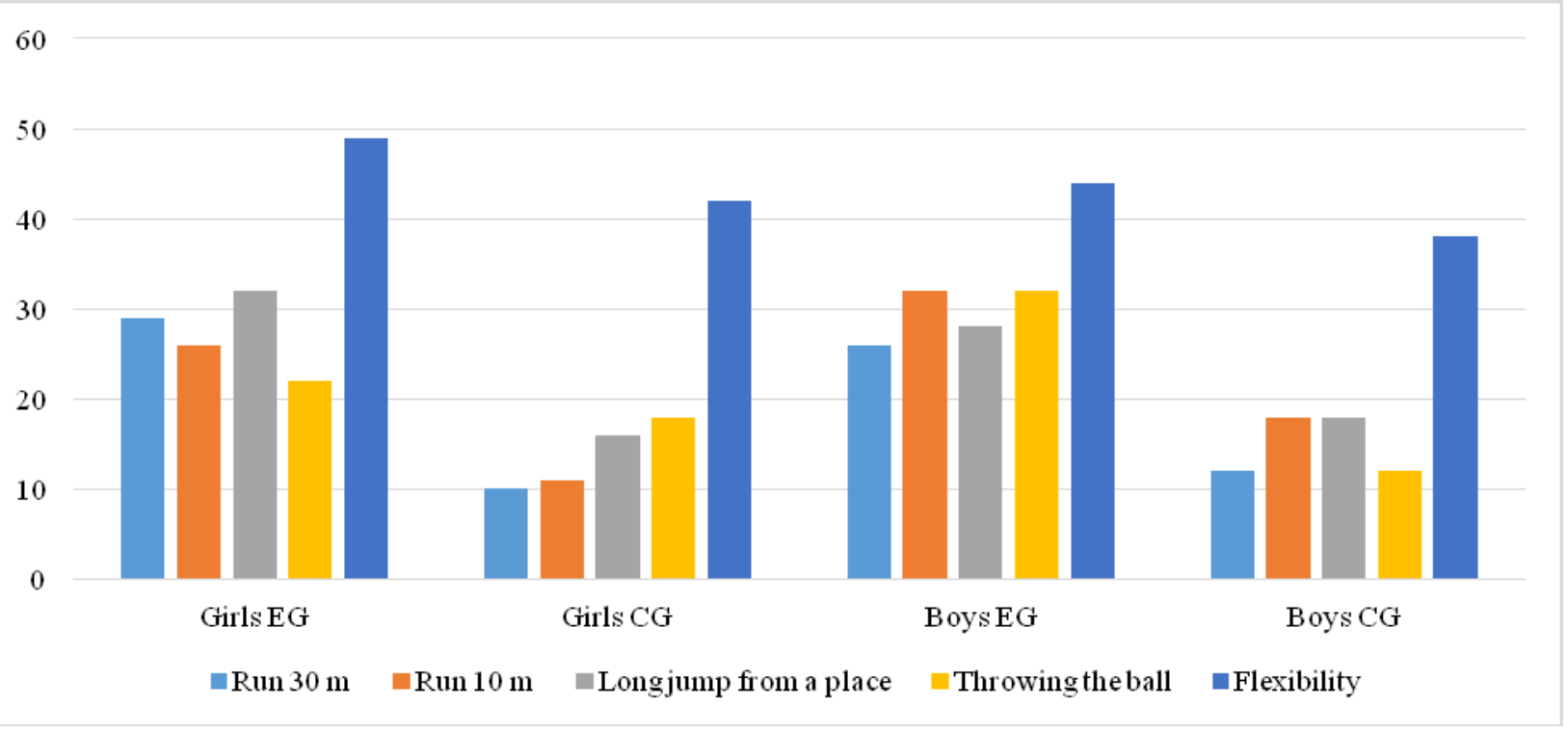

Fig. 2. Dynamics of increase in physical fitness during the experiment 
Analysis of children's illness during the year showed that in the experimental group, children are significantly less likely to suffer from various diseases during the year. The data is presented in table 1.

Table 1. Indicators of children sick days' quantity per preschool child

\begin{tabular}{|l|c|c|c|}
\hline \multirow{2}{*}{ Age } & \multicolumn{2}{|c|}{ Before experiment } \\
\cline { 2 - 4 } & $\begin{array}{c}\text { Before } \\
\text { experiment }\end{array}$ & $\begin{array}{c}\text { After } \\
\text { experiment }\end{array}$ & Remainder \\
\hline Experiment group & 5,6 & 4,1 & 1,5 \\
\hline Control group & 6,1 & 5,2 & 0,9 \\
\hline
\end{tabular}

The experimental groups in all the studied tests have higher indicators than in the control group.

After analyzing the results of the best athletes in the world and Russia and the forecast for the coming years, we can say with confidence that if current trends continue in the near future, we can expect:

It should be noted that the use of the health-saving environment organization models in the implementation of educational standards in preschool education based on the interaction of the entire team, all specialists of preschool educational institution with the inclusion of specialists for scientific and methodological support, helps not only to increase the child's level of development, but also the interest of all professionals to communicate between specialists.

Improving the educational process in accordance with the Federal state educational standard leads to a chain reaction to improving the professional competence of a modern teacher working in a preschool institution. One of the indicators of professional competence of a teacher is his ability to self-development. The main criteria for selfdevelopment of preschool teachers are: effectiveness of professional pedagogical activity, creative growth of teachers, introduction of new pedagogical technologies in the educational process.

\section{Conclusions}

We came to the conclusion that the use of this model contributes to a positive impact on the child development. It is the main result when using a health-saving environment in a preschool educational institution.

\section{References}

1. V.A. Martynova, Modern Applied Science, 8(6), 306-312 (2014)

2. Federal state statistics service. URL: https://www.gks.ru/folder/13721

3. G.R. Aizyatullova, Bulletin of science's development and education, 5, 233-235 (2013)

4. A.S. Kuznetsov, Z.M. Kuznetsova, Russian Journal of Physical Education and Sport, 14(4), 5-7 (2019). DOI: 10.14526/20704798-2019-14-4-5-7

5. F.S. Gazizova, T. N. Galich, R. F. minnullina, A. R. Nurieva, Language and actual problems of education. Proceedings of the V International scientific and practical conference (Moscow, 210-216, 2020)

6. V.A. Martynova, F.R. Zotova, Theory and practice of physical culture, 7, 83-86 (2009)

7. M.M. Bezrukikh, E.S. Loginova, E.M. Partsalis, Human Physiology, 41(4), 356-366 (2015)

8. 8. V. D. Sonkin, V. V. Zaitseva, Theory and practice of physical culture, 7, 10 (2011)

9. O.V. Kuznetsova, V. D. Sonkin, human Physiology, 35(6), 94-102 (2009)

10. T.G. Kovalenko, A.P. Shklyarenko, D.A. Ulyanov, U.G. Degtyarenko, Theory and practice of physical culture, 10, 101 (2015)

11. M.M. Bezrukikh, N.N. Terebova, L.V. Morozova, Human Physiology, 35(2), 248-251 (2009)

12. R. Ivanova, I. Berechikidze, F. Gazizova, E. Gorozhanina, N. Ismailova, Education 3-13, 48(6), $704-715$ (2020)

13. V.N. Zolotov, Z.M. Kuznetsova, Theory and practice of physical culture, 4, 91-92 (2009)

14. 14. V.V. Sudar V. V., Materials of the scientific and methodological conference of the teaching staff of the Kuban state University of physical culture, sports and tourism $(1,223-224,2019)$

15. C. Almond, AustNurs J, 6, 1-4 (1998)

16. S. Grobing, Korper-erziehung, 44(3), 89-95 (1995)

17. V. Gulmans, K. de Meer, N. van Veldhoven, Book of final Program and Abstracts 20. European CF Conference (Brussels, 1995)

18. C. Richter, International Journal of Physical Education. A Review Publication, 3, 101-106 (2007) 